\title{
Grounding system impedance characterization using FEM
}

\author{
Jose-M. Bueno-Barrachina $^{1}$, S. Catalan-Izquierdo ${ }^{1}$ and Cesar-S. Cañas-Peñuelas ${ }^{1}$ \\ ${ }^{1}$ Institute of Electrical Technology \\ Universidad Politécnica deValencia \\ Edificio 5E, Tercera Planta \\ Camino de Vera, S/N, 46022 Valencia (Spain) \\ Phone/Fax number: +34 96 3877593, +34 963877599 \\ e-mail: jmbueno@die.upv.es, scatalan@die.upv.es, cscanas@ite.upv.es
}

\begin{abstract}
.
The exact knowledge of the grounding system impedance, including its expected variability, is a matter of paramount importance in the design of medium and high voltage infrastructures. The principles underlining the physical processes involved in grounding are well established and so are the engineering concepts regarding safe operation of the grounded systems. Quite a few theoretical expressions are widely used in the project stage of any installation.

Unfortunately, these expressions are only valid for simple geometries and simplified material characteristics. Uncertainty arise from the intrinsic complexity of the grounding environment: buried grids and rods, reinforced concrete foundations surrounding them, weather dependent and non-uniform soil characteristics, etc

To overcome these limitations, in this paper the finite element method is applied to obtain the grounding impedance and the potential distribution around a real grounding system excited with sinusoidal currents at several frequencies.

Additionally, for validating purposes, a single vertical ground rod has been simulated and compared with the results obtained by other authors.

FEM commercial software, in addition to some specific purpose user functions, has been used.

The method presented in this paper can be applied to any real geometry, electrode configuration and type of soil.
\end{abstract}

\section{Key words}

Grounding systems, protection systems, finite element method, soil properties, high frequency.

\section{Introduction}

The behavior of the grounding system is a key aspect not only for the correct operation of the electrical system but also for the safety of the people living near or working at electrical infrastructures.
The grounding system includes the metallic electrode, defined by its geometrical dimensions and conducting material composition, and the electrolytically conducting ground, mainly soil, defined by resistivity, permittivity and permeability.

Ground system behavior is highly dependent on the electrode geometry, on the input current wave characteristics and on the electromagnetic properties of the ground. Models based on direct (constant) current are static approximations and become useless at high frequencies [1] because eddy current and displacement current are no longer negligible. In addition, al high frequencies, the shrinking wavelength and the grounding system dimensions become comparable [2], thus distributed parameter models are mandatory.

Fig. 1. shows a high-frequency lumped-parameters Tcircuit in a single vertical rod electrode where the series circuit represents the resistance of the metallic electrode and the overall inductance, the parallel circuit represents ground resistance and capacitance and the series circuit partition point varies according to the frequency-varying current penetration along the rod. This kind of models can provide a reasonable estimate for the ground impedance and may be used in electric system calculations, but are unable to estimate safety related magnitudes such as touch and step voltage or transferred voltages, much less these models can provide the ground surface potential profile or the current density distribution inside the ground.

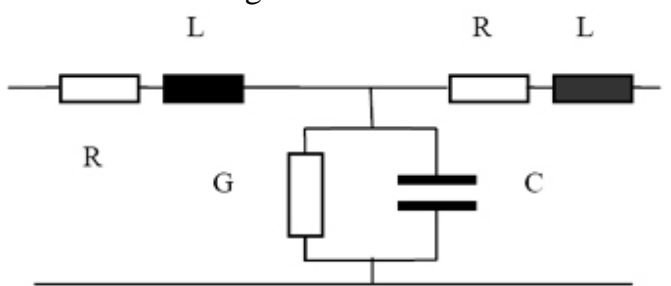

Fig. 1. High-frequency lumped-parameters equivalent circuit for a single vertical ground rod [1]. 
When separation between ground electrodes is not enough to guarantee electrical independence it is also needed to take into account mutual resistance, mutual inductance and mutual capacitance[3]. For example, Fig. 3 shows an equivalent circuit for the double rod ground system sketched in Fig.2.

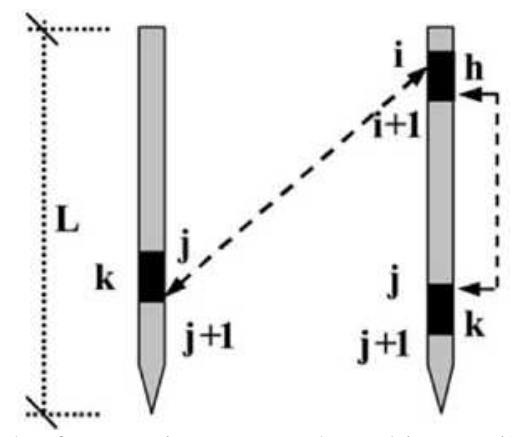

Fig. 2. Sketch of a generic segment, h, and its possible couplings with other partitions, $\mathrm{k}$, of the grounding system [3;4].

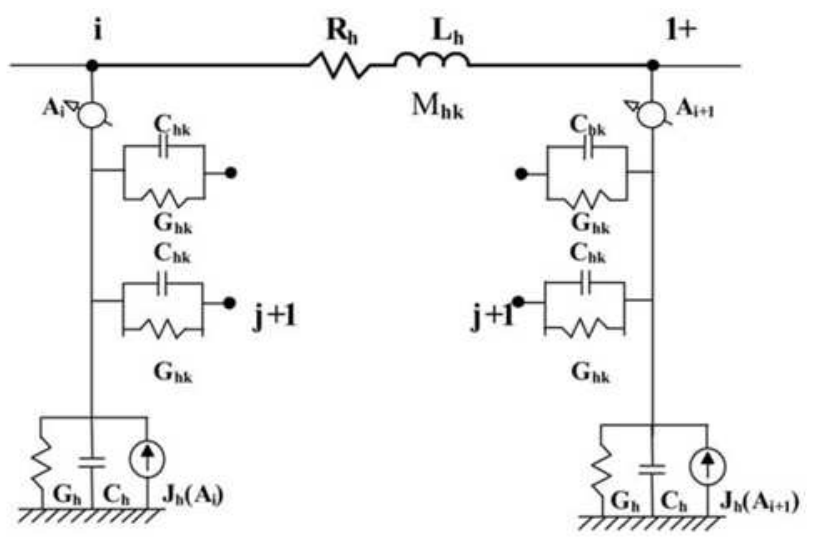

Fig. 3. Equivalent electrical network of a generic partition, h; the branches represent self parameters $\left(R_{\mathrm{h}}, L_{\mathrm{h}}, G_{\mathrm{h}}\right.$ and $\left.C_{\mathrm{h}}\right)$ and mutual parameters $\left(M_{\mathrm{hk}}, R_{\mathrm{hk}}\right.$ and $\left.C_{\mathrm{hk}}\right)$ between $\mathrm{h}$ and k partitions; the ideal current source $\left(J_{\mathrm{h}}\right)$, which simulates the ionization, is controlled by the current drained to ground, $A_{\mathrm{i}}$ and $A_{\mathrm{i}+1}$, along each transversal branch of the equivalent circuit [3].

Circuit complexity and parameter uncertainty in real grounding systems make unpractical using this classic approach. Simplifications and approximations are currently applied in the grounding design stage and, as a result, once finished the construction and measured the grounding system, modifications are not rare.

The FEM approach presented in this paper is inherently a distributed parameters method and takes directly into account resistive, inductive and capacitive mutual effects. Ground ionization is also integrated as an electric-fielddependent material characteristic.

This paper shows the 3-D model developed for a real ground system (coded as CPT-LA-22/0.5 by the transmission and distribution company Iberdrola) and some of the main results obtained.

Electromagnetic field and current density are evaluated for frequencies ranging from $0 \mathrm{~Hz}$ to $100 \mathrm{MHz}$ and, from them, the surface potential distribution and the ground system complex impedance are obtained. Touch voltage, step voltage, transferred voltages and ground potential rise are straightforward conclusions.

\section{CPT-LA-22/0.5 electrode configuration}

The grounding electrode configuration CPT-LA-22/0.5 has been choose because it is a widely used standardized grounding system for distribution poles in medium voltage networks.
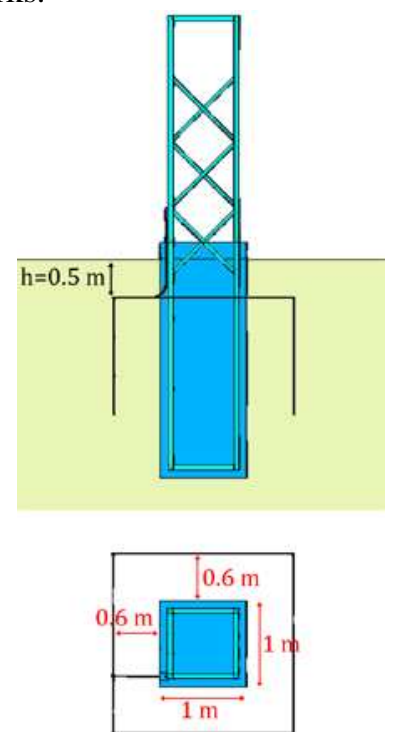

Fig. 4. CPT-LA-22/0.5 pole grounding system.

This pole is a lattice steel structure made of metallic angle sections. The pole is directly embedded into a concrete foundation and is connected to a $50 \mathrm{~mm}^{2}$ wire that define a square ring with $\varnothing 14 \mathrm{~mm} /$ lenght $1.5 \mathrm{~m}$ copper-plated rod grounding electrode at each corner. The ring is typically buried at $0.5 \mathrm{~m}$ depth (See Fig. 4).

\section{Grounding system model}

A realistic model of the system grounding has to include, at least, every current-carrying element and its surrounding environment, that is:

- All metallic (galvanized steel) components of the tower embedded in the concrete foundation (e.g., rebars, stub angles, buried portions of structure legs, etc.).

- The concrete foundation.

- The copper conductor connecting the metallic structure of the pole with the electrode ring and its insulating tube.

- The grounding electrode itself (ring, rods and welded joints).

- The surrounding soil.

All of these components are characterized by their resistivity, permittivity and permeability. Only for the sake of comparability with previously published results, in this paper we assume constant parameters in every component (See Table 1, some of them are quite different from real values). These parameters have been taken from the literature $[1 ; 4]$. It must be stressed, however, that the model has also been evaluated in a more realistic environment taking into account temperature and watercontent parameter dependence. 
Table 1. Material electrical properties.

\begin{tabular}{|c|c|c|c|c|}
\hline \multirow[b]{2}{*}{$\begin{array}{c}\text { Grounding } \\
\text { system } \\
\text { element }\end{array}$} & \multirow[b]{2}{*}{ Material } & \multicolumn{3}{|c|}{ Material electrical properties } \\
\hline & & 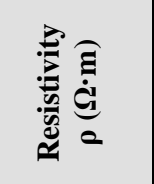 & $=$ & 总 \\
\hline pole & $\begin{array}{l}\text { galvanized } \\
\text { steel }\end{array}$ & $7.2 \mathrm{E}-7$ & 1.008 & 1 \\
\hline foundation & concrete & 3000 & 1 & 23 \\
\hline $\begin{array}{l}\text { connecting } \\
\text { wire and ring }\end{array}$ & copper & $1.7 \mathrm{E}-8$ & 1 & 1 \\
\hline $\begin{array}{l}\text { insulating } \\
\text { tube }\end{array}$ & PVC & 3000 & 1 & 2 \\
\hline rods & $\begin{array}{c}\text { copper- } \\
\text { plated steel }\end{array}$ & $1.7 \mathrm{E}-8$ & 1 & 1 \\
\hline soil & sandy loam & 100 & 1 & 4 \\
\hline
\end{tabular}

Since the injected current define an electric field much lower than the critical ionization value[5-9], no ionization channel around the electrodes nor lateral discharges nor ground breakdown can be observed.

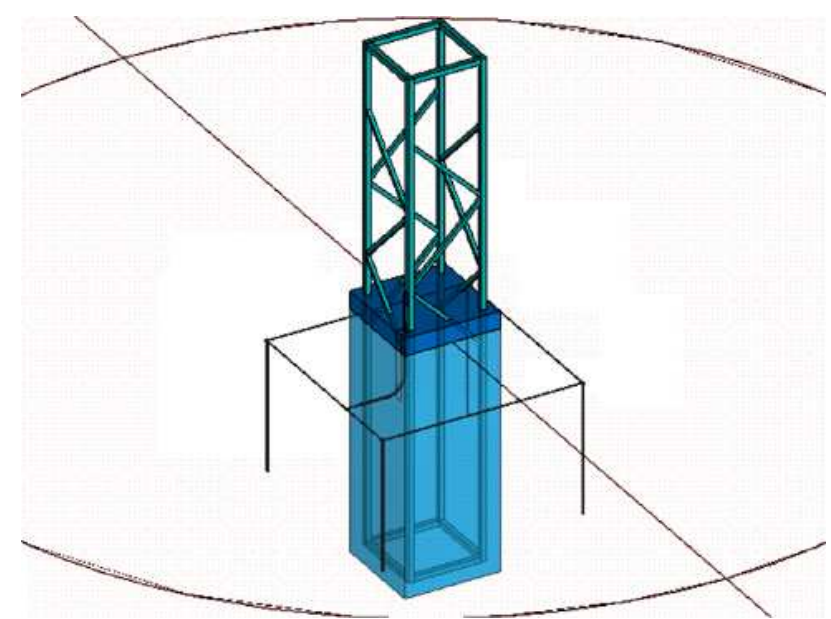

Fig. 5. Grounding system model of a $\overline{\mathrm{MV} \text { tower. }}$

\section{Performed simulations}

Simulations consist of the injection of a specified sinusoidal current at the MV pole peak to obtain the voltage distribution, the electric field and the current density distribution in every component. Fault intensity $\overrightarrow{I_{d}}=1000+i 0 \mathrm{~A}$ has been assumed. This value was selected taking into account that real fault current intensity in these MV distribution systems ranges from 500 to $2228 \mathrm{~A}$ for $20 \mathrm{kV}$ nominal voltage line.

In order to determine the frequency dependence characteristics of the grounding system impedance, sixteen simulations ranging from 0 to $100 \mathrm{E} 6 \mathrm{~Hz}$ logarithmically distributed have been used.

The impedance of the grounding system model $(\overrightarrow{Z(j \omega)})$ has been evaluated for every frequency. $\overrightarrow{V_{\max }(j \omega)}$ is the highest rms voltage obtained in the simulation (which is always located at the top of the pole).

$$
\overrightarrow{Z(j \varpi)}=\frac{\overrightarrow{V_{\max }(j \varpi)}}{\overrightarrow{I_{d}}}
$$

In order to set up and execute such a large number of simulations in a very broad range of frequencies, ANSYS multiple-run simulation capability with varying parameters (PCVP) has been extensively used.

All the simulations have been run considering the component $(\mathrm{X}, \mathrm{Y}, \mathrm{Z})$ magnetic current segments and the current flow. The authors have checked the accuracy of the numerical results also for more extended configurations.

As usual, model limits have been increased to appropriate values.

\section{Numerical results}

The results of all the simulations are summarized in Table 2. For each table entry (frequency of the current intensity applied versus maximum rms voltage obtained in the simulation and the calculated impedance.

Figs. 6, 7 and 8 show the voltage 3-D distribution inside and on the surface of the grounding system for a constant current intensity $I_{d}=1000 \mathrm{~A}$. Results are presented in two complementary ways in order to show most of the details: figures at the top are equipotential volumes while bottom figures are equipotential surfaces.

Fig.6 shows a cross-section of the model by a vertical centered plane equidistant from the rods. Fig.7 shows a cross-section by a vertical plane containing two diagonally opposite rods. Fig.8 shows a horizontal plane, seen from above, at the square ring electrode level.

As expected, the highest electric potential is always located at the top of the pole where current is injected and is proportional to the apparent impedance of the ground system. Voltage is distributed around every metallic component; this effect is clearly seen as equipotential surfaces surrounding rods, wire ring (see Figs. 6, 7) and the steel structure inside the foundation (see Fig. 8).

Voltage distribution, however, is quite different comparing Fig.6 and. Fig.7. As a result, touch voltage and step voltage are significantly different at each direction.

The effect of the pole components embedded in the foundation is especially important at higher frequencies. This effect is even increased when, instead of considering a dry concrete as this paper shows, real wet concrete properties are taking into account.

Real soil properties and its continuous variability have a major impact on the results. On the other hand, results are quite independent from the electrical properties of the conducting components.

The results confirm that $|\overrightarrow{Z(j \omega)}|$ is frequency independent and almost equal to the static input impedance $\left(\mathrm{R}_{0}=12 \Omega\right.$, in this case) up to a frequency of about $100 \mathrm{kHz}$. For higher frequencies, the model exhibits inductive behavior whereas for frequencies close to $100 \mathrm{MHz}$ the behavior is capacitive. 

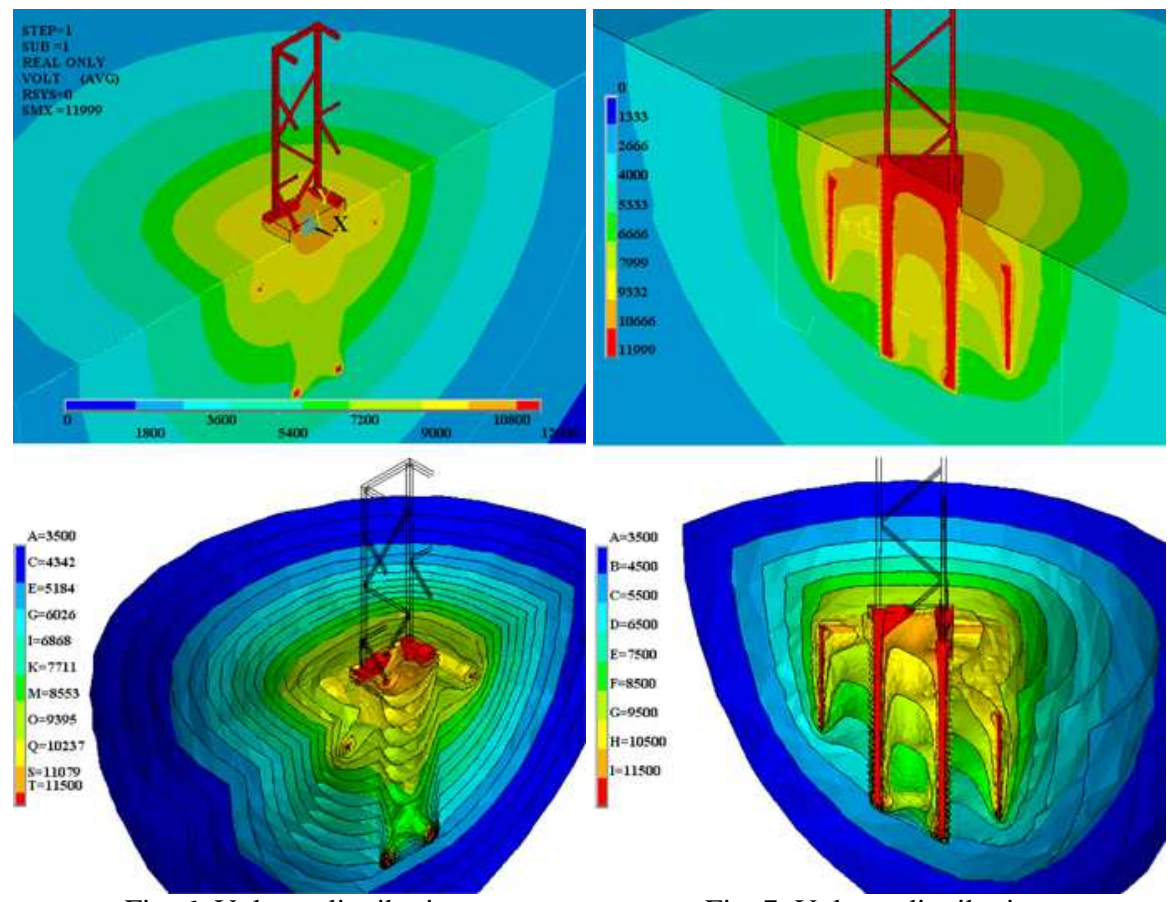

Fig. 6: Voltage distribution.

Vertical plane-parallel cross-section.
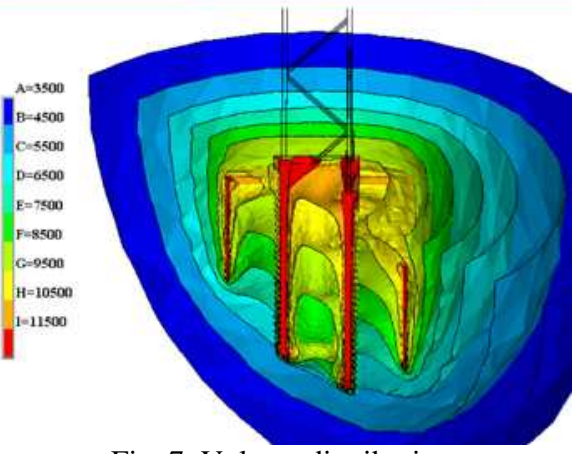

Vertical diagonal plane cross-section
Fig. 7: Voltage distribution.
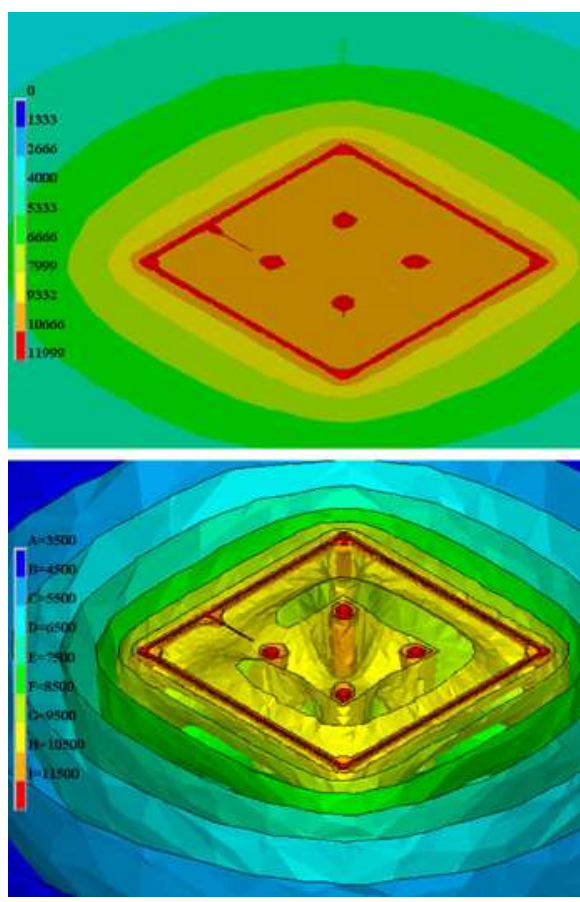

Fig. 8: Voltage distribution.

Horizontal plane at electrode ring level
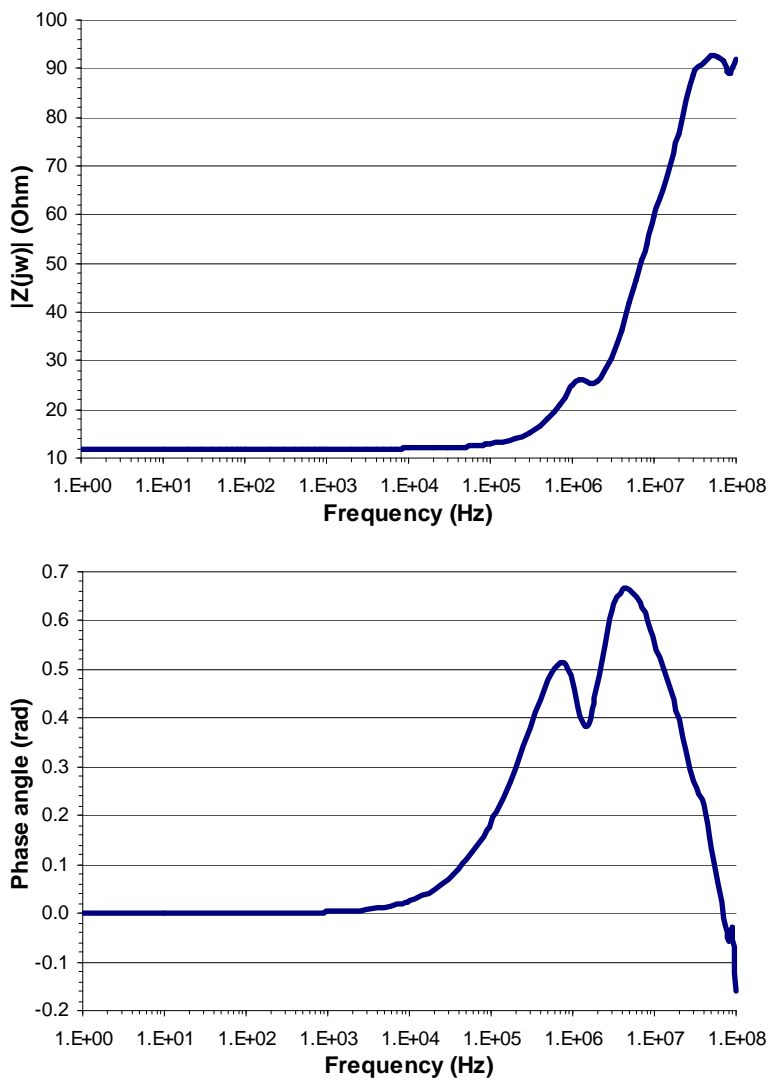

Fig. 9. Frequency response of the ground model.

In the frequency response curves (See Fig. 9), a partial resonance appears at about $1 \mathrm{MHz}$. High-frequency lumped-parameter models [3;9] also show this resonance. Fig. 9 shows another resonance just before $100 \mathrm{MHz}$.
Table 2. Simulation results

\begin{tabular}{|c|c|c|c|}
\hline $\begin{array}{l}\text { Frequency } \\
\text { (Hz) }\end{array}$ & $\underset{(\mathbf{k V})}{\left|\mathbf{V}_{\max }(\mathbf{j} \omega)\right|}$ & $\begin{array}{c}|\mathbf{Z}(\mathbf{j} \omega)| \\
(\boldsymbol{\Omega})\end{array}$ & $\begin{array}{c}\text { Phase angle } \\
\text { (rad) }\end{array}$ \\
\hline 0 & 12.00 & 12.00 & 0.00 \\
\hline 3000 & 12.00 & 12.00 & 0.01 \\
\hline 6000 & 12.01 & 12.01 & 0.01 \\
\hline 7000 & 12.01 & 12.01 & 0.02 \\
\hline 10000 & 12.02 & 12.02 & 0.02 \\
\hline $100 \mathrm{E}+03$ & 12.86 & 12.86 & 0.19 \\
\hline $1 \mathrm{E}+06$ & 24.99 & 24.99 & 0.47 \\
\hline $1.25 \mathrm{E}+06$ & 26.19 & 26.19 & 0.40 \\
\hline $1.50 \mathrm{E}+06$ & 25.71 & 25.71 & 0.38 \\
\hline $1.75 \mathrm{E}+06$ & 25.33 & 25.33 & 0.42 \\
\hline $2 \mathrm{E}+06$ & 25.67 & 25.67 & 0.47 \\
\hline $3 \mathrm{E}+06$ & 30.58 & 30.58 & 0.62 \\
\hline $4 \mathrm{E}+06$ & 36.41 & 36.41 & 0.66 \\
\hline $5 \mathrm{E}+06$ & 41.75 & 41.75 & 0.66 \\
\hline $6 \mathrm{E}+06$ & 46.45 & 46.45 & 0.65 \\
\hline $7 \mathrm{E}+06$ & 50.52 & 50.52 & 0.63 \\
\hline $8 \mathrm{E}+06$ & 54.04 & 54.04 & 0.60 \\
\hline $9 \mathrm{E}+06$ & 57.10 & 57.10 & 0.58 \\
\hline $10 \mathrm{E}+06$ & 59.78 & 59.78 & 0.56 \\
\hline $20 \mathrm{E}+06$ & 76.53 & 76.53 & 0.40 \\
\hline $30 \mathrm{E}+06$ & 88.64 & 88.64 & 0.27 \\
\hline $40 \mathrm{E}+06$ & 91.04 & 91.04 & 0.22 \\
\hline $50 \mathrm{E}+06$ & 92.71 & 92.71 & 0.13 \\
\hline $60 \mathrm{E}+06$ & 92.32 & 92.32 & 0.06 \\
\hline $70 \mathrm{E}+06$ & 91.49 & 91.49 & -0.01 \\
\hline $80 \mathrm{E}+06$ & 89.01 & 89.01 & -0.06 \\
\hline $90 \mathrm{E}+06$ & 89.94 & 89.94 & -0.03 \\
\hline $100 \mathrm{E}+06$ & 91.94 & 91.94 & -0.16 \\
\hline
\end{tabular}


This kind of resonances at higher frequencies only appears in some distributed-parameter models which are only applicable to very simplified systems [2].

Even in real ground system measurement precision is very hard to achieve as frequency increase, so simulations, as presented in this paper, seems to provide better estimates [2;3].

As Fig.9 shows, this ground system is appropriate for low frequency current fault up to some $\mathrm{kHz}$. For frequencies higher than a few hundreds of $\mathrm{kHz}$ the behavior quickly worsens and for $\mathrm{MHz}$ is, probably, useless.

As expected, the grounding system shows a resistive behavior up to increasing frequencies as the rod length decreases and as the soil resistivity increases [10]. Also as expected, capacitive behavior shows al lower frequencies for short rod electrodes and highly resistive soils, otherwise, the grounding electrode behavior is mostly inductive[ $8 ; 11]$.

Provided that the proposed model suits equally well to any shape and position of the grounding electrodes, it can also be used to evaluate the surge impedance of any grounding systems.

\section{Model validation}

This model has been compared numerically to various grounding system configurations available in the literature [1;9].

In addition, in order to achieve a much more exact validation, a grounding system model formed by a single vertical ground rod ( 9 meter length, $20 \mathrm{~mm}$ diameter), in a $100 \Omega \cdot \mathrm{m}$ resistivity and 4 relative permittivity soil has been evaluated only for comparison purposes.

Again, the simulations have been conducted assuming a fault current intensity $\overrightarrow{I_{d}}=1000+i 0 \mathrm{~A}$. In this model, frequency values ranging from 0 to $1.25 \mathrm{E} 6 \mathrm{~Hz}$ spaced in logarithmic distribution have been used.

Fig. 10. shows the magnitude of the ground system impedance, referred to the static (d.c.) impedance, as a frequency function. Fig. 11 also shows the angle of the complex impedancia.

This configuration is an exact match of that published by Martínez-Velasco et al. [9]. A detailed comparison of the results shows quite a good agreement:

- Ground system impedance is almost constant until $100 \mathrm{kHz}$.

- From $100 \mathrm{kHz}$ until $1 \mathrm{MHz}$ the system increases its inductive behavior as the angle increasing slope shows and the impedance magnitude also increase steadily.

- At about $1 \mathrm{MHz}$ appears a local resonance at a local maximum (voltage lead) angle of $0.76 \mathrm{rad}$ $\left(43.82^{\circ}\right)$. Impedance magnitude reaches 3.4 its static d.c. value.

Fig. 12 shows the current distribution in a horizontal crosssection of this grounding system located at $0.5 \mathrm{~m}$ depth. System frequency is $1.25 \mathrm{MHz}$.

As expected at this frequency, conduction is limited to the most outer rod layer and the soil
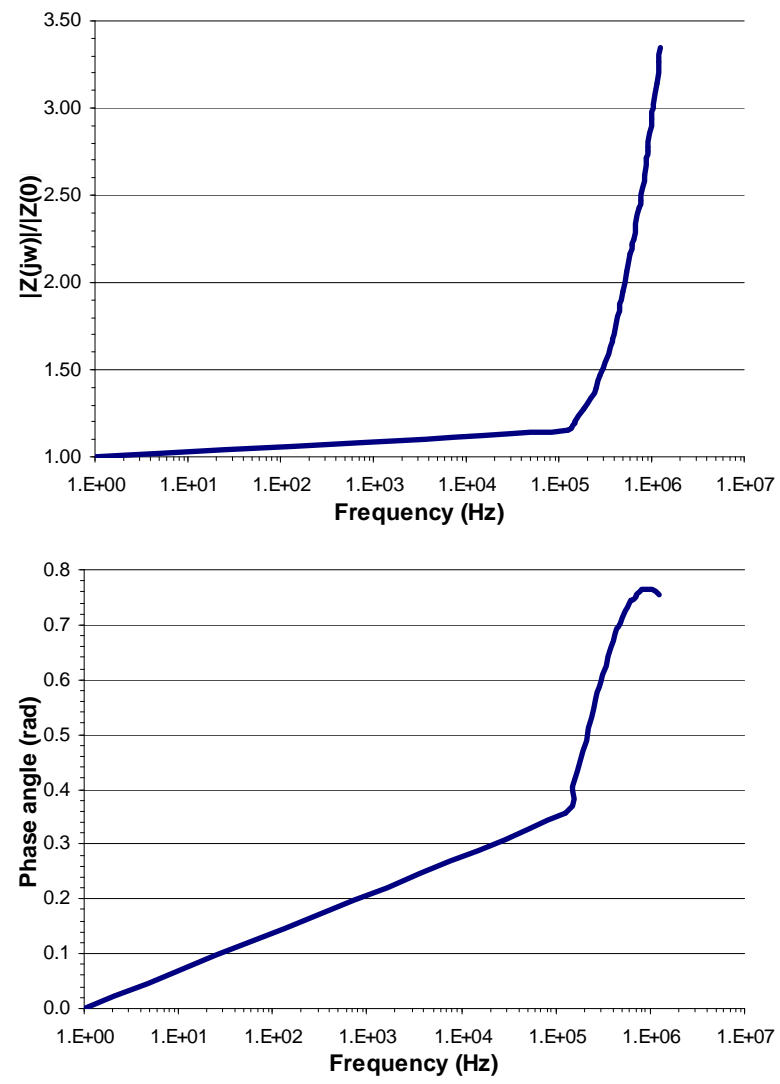

Fig. 10: Frequency response of the ground model.

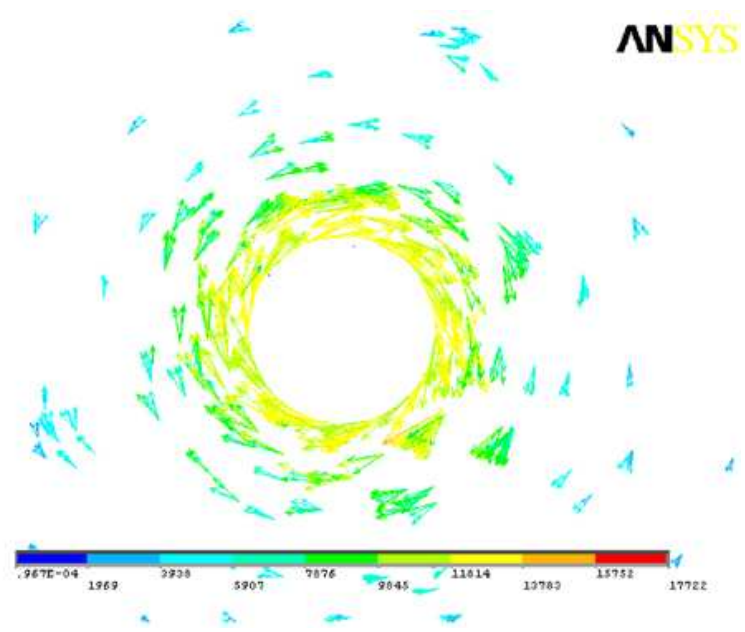

Fig. 11: Intensity current distribution.

\section{Conclusions and remarks}

In this paper the feasibility of the FEM for the detailed design of complex grounding systems has been showed. The method is equally appropriate for low and high frequencies and for steady-state and transient-state.

Even though, for comparison purposes, the selected grounding electrode (a real standardized CPT-LA-22/0.5 electrode) is no very complex, the method developed is absolutely general and applicable to any other one.

For validating purposes, the results have been extensively compared with published measurements, as well as with analyses of the same ground system based on highfrequency lumped-parameter models and high-frequency distributed-parameter models. 
The numerical results of the simulations are in good agreement with operation results. Regarding the authors' previous studies $[1 ; 4]$ the proposed model yields more accurate predictions.

\section{References}

[1] C.-S. Cañas-Peñuelas, S. Catalan-Izquierdo, J.-M. BuenoBarrachina, "Optimización de electrodos de puesta a tierra", Electrical Engineering Electronic Journal 1 (1) (2009) 245.

[2] L. Grcev and M. Popov, "On high-frequency circuit equivalents of a vertical ground rod", IEEE Transactions on Power Delivery 20 (2) (2005) 1598-1603.

[3] F. M. Gatta, A. Geri, S. Lauria, "Backflashover simulation of HV transmission lines with concentrated tower grounding", Electric Power Systems Research 73 (3) (2004) 373-381.

[4] J.-M. Bueno-Barrachina, C.-S. Cañas-Peñuelas, S. CatalanIzquierdo, A. Quijano, "Modelization of earth electrode excited by atmospheric discharges based on FEM", Renewable Energy and Power Quality Journal 6 (2008) 427.
[5] G. Ala, E. Francomano, E. Toscano, F. Viola, "Finite difference time domain simulation of soil ionization in grounding systems under lightning surge conditions", Applied Numerical Analysis \& Computational Mathematics 1 (1) (2004) 90-103.

[6] K. F. Casey, "Electromagnetic shielding behavior of wiremesh screens", IEEE Transactions on Electromagnetic Compatibility 30 (3) (1988) 298-306.

[7] L. Grcev and F. Dawalibi, "An electromagnetic model for transients in grounding systems", IEEE Transactions on Power Delivery 5 (4) (1990) 1773-1781.

[8] L. Grcev, "Improved earthing system design practices for reduction of transient voltages", in: CIGRE Session, 1998,

[9] J. A. Martinez-Velasco, A. I. Ramirez, and M. Dávila, Overhead Lines in Power System Transients - Parameter Determination, 1 ed. J. A. Martinez-Velasco, Ed. CRC Press, 2010, pp. 17-135.

[10] C. Gary, "L'impedance de terre des conducteurs enterrés horizontalement", in Proc. International Conference on Lightning and Mountains, Chamonix, France 1994 ,

[11] M. I. Lorentzou and N. D. Hatziargyriou, "Effective design of extended grounding systems", International Journal of Applied Electromagnetics and Mechanics 13 (14) (2002) 291-297. 